\title{
Evaluating Energy Sector Investments: Calculating Volatility
}

\author{
Edson de Oliveira Pamplona, ${ }^{1}$ Marina Carvalho Brandão, ${ }^{1}$ \\ José Arnaldo Barra Montevechi, ${ }^{1}$ Alexandre Ferreira de Pinho, ${ }^{1}$ \\ Valério Oscar Albuquerque, ${ }^{2}$ and Paulo Rotela Junior ${ }^{1}$ \\ ${ }^{1}$ Institute of Production Engineering and Management, Federal University of Itajuba, Avenida Bps 1303, Itajuba, \\ MG 37500-903, Brazil \\ ${ }^{2}$ Institute of Electrical Engineering, Federal University of Itajuba, Itajuba, MG, Brazil \\ Correspondence should be addressed to Paulo Rotela Junior; paulo.rotela@gmail.com
}

Received 2 April 2013; Revised 11 October 2013; Accepted 14 October 2013

Academic Editor: Chien-Yu Lu

Copyright (C) 2013 Edson de Oliveira Pamplona et al. This is an open access article distributed under the Creative Commons Attribution License, which permits unrestricted use, distribution, and reproduction in any medium, provided the original work is properly cited.

\begin{abstract}
A major task in assessing risks of investment projects is defining the approach to calculating the project's volatility. Looking at assorted estimation techniques, this paper calculates their volatilities. The techniques originate from authors in the area and involve project-specific variables of uncertainty. These techniques are applied to a case of electricity distribution through real options. Results are then compared. The difference between the calculated volatilities was low, leaving, in the case of the project evaluated here, the decision unchanged. The paper's contribution consists of providing a detailed presentation of calculating volatility by the methods cited and by comparing the results obtained by its application.
\end{abstract}

\section{Introduction}

The aim of this paper is to address the issue of calculating volatility on a project-specific distribution of the electricity sector. A method to be applied to the electricity sector is then presented based on the theory of real options. To obtain uncertainty (volatility), the literature offers various methods; this paper implements these methods and comes up with results and then compares them. For this analysis, traditional investment is conducted and compared with results obtained by these different methods of calculating volatility.

Why we study investments in the Brazilian Electricity Sector? We consider such a study to be justified by the following factors observed in the Brazilian Electricity Sector: the capital expenditure of most projects, the irreversibility of investments, the high volatility of energy prices on the spot market, and the vulnerability of energy prices to several exogenous variables that contribute to an increased volatility. Just as in some cases, long-term contracts are linked to ensuring the predictability of future scenarios. Therefore a detailed analysis of the issue of volatility-the variables of uncertainty-is imperative for each sector project, because volatility can vary according to these characteristics.

\section{Real Options}

One way of assessing the future as a dynamic event is through the use of real options. Real options, a tool that considers all events, are able to provide managerial flexibility in the face of changing scenarios, analyzing for every moment what options are the most advantageous. How do real options differ from financial options? The underlying asset of financial options are the papers and exchange-traded securities. The underlying asset of real options is the physical assets of companies like the machines, designs, patents, and so forth [1].

In this context, real options emerged as an innovative way of thinking about the evaluation of real assets. Indeed, it uses the model of discounted cash flow while complementing it with the concept of financial options [2].

In calculating the flexibility of real options, the only variable added to those used in traditional assessment methods 
is volatility. Volatility, however, is the most difficult variable to determine and even more complex when it comes to input parameters [3].

Copeland and Tufano [4] report that many articles have been written about the theory of real options pricing. In practical problems, however, the applications of real options (RO) are limited by the complexity of the mathematical approach, the restrictive assumption of necessary theories, and a lack of intuitive appeal. These, in fact, are the settings most authors use.

2.1. Risk-Neutral Probability. Risk neutral probability is represented by $p$ and $1-p$. It differs from objective probability in that there is a real probability but only a probability that reflects the real chance of any particular flow occurring. Copeland and Antikarov [5] stated that risk-neutral probabilities are simply a mathematical convenience designed to adjust cash flows and can thus be discounted at a risk-free rate. The authors further say that these probabilities are also known as the adjusted odds risk or probability of hedging.

To obtain the value of one share of an option to purchase on Date 0 , it is necessary only to know the risk-free rate, the increments of ascent and descent, and the possible values of the call option on a date. The theory of risk-neutral probabilities shows that the objective probabilities do not interfere with the value found for the option price. Hence, there is no need to adjust the discount rate to calculate the risk value of the option [6]. Equation (1) is called backward induction, a recursive method to derive the option value, while the risk-neutral probability is described in (2), where $u$ and $d$ are multipliers of ascent and descent of the action and $c_{u}$ and $c_{d}$ are option values in case of increase, or decrease respectively:

$$
\begin{gathered}
c=e^{-r t}\left(c_{u} p+c_{d}(1-p)\right), \\
p=\left(\frac{e^{r t}-d}{u-d}\right) .
\end{gathered}
$$

2.2. Binomial Model. To price real options, Cox et al. [7] make use of probability theory to develop a binomial approach (3). This approach employs simpler mathematics to achieve isomorphic results for the calculation of Ito, used by Black and Scholes [8]. The difference in the models is that the discrete mathematics of algebraic nature used in the binomial model are easier to understand than the stochastic differential equations of Black and Scholes' model:

$$
C_{0}=(S \times \emptyset[n \geq a \mid T, p])-\left(X \times R^{-T} \times \emptyset\left[n \geq a \mid T, p^{\prime}\right]\right),
$$

$$
\begin{aligned}
& p=\left(\frac{R-d}{u-d}\right), \\
& p^{\prime}=\left(\frac{u}{R}\right) \times p,
\end{aligned}
$$

where $C_{0}=$ the value of the call optionbecause random; $a=$ the minimum number of upward movements that the action must have in the next $n$ periods to finish the option in the money (the smallest nonnegative integer and greater than $\left.\log \left(X / S \times d^{n}\right) / \log (u / d)\right) ; p=$ risk-neutral probability, $n=$ number of periods to maturity; $S_{0}=$ current price of the asset, $X=$ exercise price; $R=1+r$ (risk free rate for a period); $\emptyset[\cdots]=$ complementary binomial distribution.

Equations (4) and (5) describe the risk-neutral probabilities of the binomial model. In the binomial pricing formula developed by Cox et al. [7], two factors are important: $u$ and $d$ are the multipliers of the movements of climb (up) and fall (down) of the gross value at the beginning of the period. These formulas described in (6) are based on the volatility $(\sigma)$ of the underlying asset and the $n$ number of intervals in the period until the expiration time $T$ :

$$
\begin{gathered}
u=e^{\sigma \sqrt{T / n}}, \\
d=e^{-\sigma \sqrt{T / n}} .
\end{gathered}
$$

\section{Volatility}

According to Mun [1], one of the most difficult input parameters for estimating the value of real options is the volatility of cash flows. In obtaining them, many methods can be employed. In real options, however, the best method to use is the consolidated approach of uncertainty (this logarithmic return on value).

This method is used primarily when calculating the volatility of assets with cash flow. Its main advantage is that it includes the ability to accommodate certain negative flows, and, in applying a more rigorous analysis, it provides a more accurate and conservative estimate of the volatility of assets analyzed. However, there is a need to use this method to obtain simulation volatility.

3.1. Consolidated Approach to Uncertainty. According to Copeland and Antikarov [5], the second step to obtain the value of a project through real options is the assembly of the event tree. Here the set of uncertainties is demonstrated, and their combination influences the volatility of the project. The main objective of the event tree is to model the uncertainty that, over time, influences the value of the underlying asset.

As in most cases, the uncertainties are multiple projects. These can be combined, through the distribution of returns on the project, into a single uncertainty. This done using the Monte Carlo analysis. Such an approach is called a consolidated approach of uncertainty.

Copeland and Antikarov [5] stated through Samuelson's theorem [9] that, despite future cash flows presenting a certain pattern, the rate of return on a project behaves randomly. This is because all information about the behavior of future cash flows is already presently reflected in the underlying asset; if expectations are confirmed, investors will then obtain exactly the expected return. But if the cash flow changes according to random events (represented by the uncertainty), then the return will also behave randomly. In summary, in the calculation of options volatility $(\sigma)$ plays an important role. It translates the uncertainties of projects, making it possible to construct, using (6), a binomial tree based on geometric Brownian motion. 
This implies that, as stated earlier, the uncertainties related to the projects can be combined into a single uncertainty. Such an uncertainty-the consolidated uncertaintywill directly influence future cash flows. So, the volatility needed to develop the binomial tree is the volatility of the rate of return that, as raised by Samuelson's theorem, comes from the random events that together influence the future cash flows. It can thus be obtained from the ratio of (7) and (8):

$$
\mathrm{VP}_{t}=\mathrm{VP}_{0} e^{r t}
$$

For calculation purposes, it is supposed that $t=1$. So if you have the following equality:

$$
\ln \left(\frac{\mathrm{VP}_{1}}{\mathrm{VP}_{0}}\right)=r=X,
$$

where $\mathrm{VP}_{1}$ is the present value of future cash flows in Period 1 , and $\mathrm{VP}_{0}$ is the present value of future cash flows at Date 0 . With the completion of the Monte Carlo simulation, the standard deviation of the variable $r$ is obtained (return rate of the first period of the project). That is, the volatility of the project is variable $X$.

The system used by Herath and Park [10] is similar to that used by Copeland and Antikarov [5] but differs in how it applies the Monte Carlo simulation. Authors Copeland and Antikarov [5] as well as Mun [1] advocate that the Monte Carlo simulation should be applied only to the numerator, keeping the denominator as a static value of the net present value of the project. Because Herath and Park [10] claim simulation in both factors of (8), a significant increase in the volatility is generated. This is because random events are inserted on both sides of the equation, without their necessarily being a correlation study between them. Section 4 will apply both methodologies to see which one obtains a more accurate value of flexibility in the design of the electricity sector in question.

3.2. Volatility in the Assessment of Real Options. The correct analysis of the value depends on the flexibility of care in handling the data as well as the development of a series of steps to obtain the input values needed to solve for this tool.

Copeland and Antikarov [5] presented a method that calculates the value of flexibility in four steps. The focus in their method is the calculation for the project, thus becoming a microview of the problem.

Mun [1] developed a method, based on the strategic vision of real options, which calculates the value of flexibility in eight steps. It is a more comprehensive method that also seeks the application of real options in project portfolio optimization and in other strategic decisions.

Based on these two methods, the present study outlines a specific method (seen in Figure 1) for solving a problem of expanding the electricity distribution through the binomial model of real options. As for the modeling of the problem, it was developed according to the precepts of modeling and simulation. This is because, according to Bertrand and Fransoo [11], those precepts can be considered axiomatic rules of quantitative research.
Step 1 applies the traditional metrics for evaluating investments and then analyzes such criteria as NPV, IRR, payback, and cost benefits. As a result, the value of the project is obtained, calculated through discounted cash flow methods.

Step 2 defines the design variables of uncertainty, which can be defined either through the knowledge of experts or by analyzing how sensitive the economic outcome of the project is to variations of each variable. In this phase, the historical data is examined to produce a forecast of future scenarios. From these parameters, one can perform a Monte Carlo simulation to obtain the value of volatility, which in this example will consider a consolidated approach to uncertainty, and their two models, Copeland and Antikarov methods (CA) and Herath and Park (HP). Finally, with the value of the project's volatility, one is able to build an event tree, where all possible values for the next period are elucidated. The event tree is the product of Step 2.

In Step 3, the event tree is used to incorporate flexibility. Aware of the possible values that a project might develop over a period, the decision maker may resort to strategies and carry out more efficiently the process of decision making. For critical analysis of possible future optimal decisions, values associated with these are incorporated into the project tree. Applying risk-neutral probabilities, these values are brought to Date 0 , and the value of the options in the project are being calculated. The result of this step is the generation of a decision tree with initiatives that maximize the value of the project according to the achievement of future scenarios.

Finally, Step 4 produces the best time to invest in the project. It also evaluates the project with flexibility, where the main output is the value of design options. The objective of this step is optimal decision making and the use of the tool applied to justify the drafting of an action plan for the project by senior management.

\section{Evaluation of Investment with Volatility}

We developed real options analysis for a project to expand capacity of a power distributor. We took into account the uncertainties present in the initial project implementation.

The company already has a concession in one area of energy supply, and forecasts suggest the growth of local consumers. In this scenario the basic network of subtransmission would not support such growth in demand. It then becomes necessary to analyze the feasibility of implementing a new substation, expanding preexisting substations, and including and increasing the capacity of subtransmission lines. The option must be considered, however, of putting off investment until the time to exercise the option is more advantageous.

The project has a lifespan of 30 years, during which time the company will pay back the investment as it depreciates. The company will also receive a portion of the gain loss arising from the implementation of new structures. Over the early years of other inputs, the investment is related to additional revenue from selling energy to the new aggregate demand. 


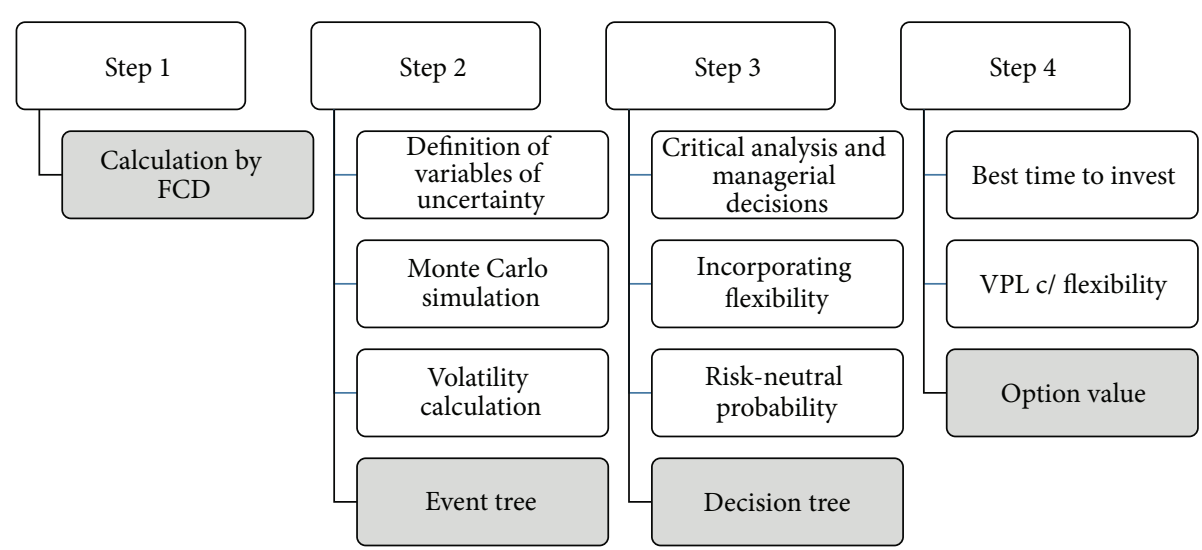

FIgURE 1: Assessment for Real Options for a case of distribution.

TABLE 1: Analysis by DCF.

Total investment in trans. + subtransmission*

$17,590.92$

Total investment feeders on primary network + underground*

Total investment primary and secondary networks*

$2,217.68$

Total investment**

$16,049.31$

$35,857.91$

Net present value (NPV) (discounted to $14.00 \%)^{*}$

$14,064.79$

Internal rate of return (IRR)

$45.73 \%$

Modified internal rate of return (MIRR) (reinv. rate $14.00 \%)$

$17.72 \%$

Benefit/cost

1.27

*Amounts in R $\$ 1,000.00$.

${ }^{* *}$ Simple sum.

The investment program was divided into short, medium, and long term. The plan was prepared in accordance with the regulation regarding the attendance of demand, providing for penalties if consumer demand is not met.

Step 1 (calculating the discounted cash flow). Considering the data supplied by the company, spreadsheets of market growth, benefits, and costs were built. This resulted in a traditional evaluation of investment, shown in Table 1. One can see that the investment is feasible, presenting a positive NPV and an IRR well above the minimum rate of attractiveness called for by the company on its investments.

The demand growth continues until the ninth period. The current maximum capacity is $177.30 \mathrm{MW}$. It is important to note that the figures are calculated according to the new assessment methodology adopted by the investment company in 2009.

Step 2 (calculation of volatility). According to the knowledge of experts, three main sources of uncertainty have been defined: demand, price, and rate of return on assets. As asserted above, multiple uncertainties can be combined into a single uncertainty. Therefore, the parameters to calculate the volatility will be discussed one by one below and then combined.
TABLE 2: Demand growth in the region.

\begin{tabular}{lcccccccc}
\hline & $\begin{array}{c}\text { Year } \\
\end{array}$ & $\begin{array}{c}\text { Year } \\
2\end{array}$ & $\begin{array}{c}\text { Year } \\
4\end{array}$ & $\begin{array}{c}\text { Year } \\
5\end{array}$ & $\begin{array}{c}\text { Year } \\
6\end{array}$ & $\begin{array}{c}\text { Year } \\
7\end{array}$ & $\begin{array}{c}\text { Year } \\
8\end{array}$ & $\begin{array}{c}\text { Year } \\
9\end{array}$ \\
\hline $\begin{array}{l}\text { Average } \\
\text { annual } \\
\text { growth }\end{array}$ & $4.8 \%$ & $3.9 \%$ & $3.9 \%$ & $4.2 \%$ & $3.9 \%$ & $4.4 \%$ & $3.9 \%$ & $3.9 \%$ \\
\hline
\end{tabular}

4.1. Demand. To define the demand forecast, historical data of the company were used, applying forecasting studies for the region by planning experts from the company. Based on the information used, it was possible to outline future demand scenarios. It was found that the average growth rate accords with Table 2 with a standard deviation of $0.32 \%$ for all periods. Normal distribution was used, after testing for normality with the data obtained.

Growth rates of demand after the ninth period are not significant, because the capacity demanded would exceed the system load that would be generated by these new investments. So if there is a subsequent increase later in the year, it would require furhter investment to meet demand.

4.1.1. Evolution of the Energy Tariff. The rate of energy distribution is defined by the government through the allowed annual revenue (AR), according to the remuneration of company assets, operating costs, and maintenance, also taking into account the efficiency of companies.

Initially, in area studies, the energy rate was considered a fixed parameter over the periods. Similarly to the study of variable demand, historical data and expert planning studies were considered, where there was a stationary trend of the variable price. Therefore, we chose to model the variable through a normal distribution with $\mu=\sigma$ and $\mathrm{R} \$ 182.39=$ $\$ 14.40$.

4.1.2. Rate of Return on Assets Defined by the Regulatory Agency. The weighted average cost of capital is the rate of return set by Brazilian Electricity Regulatory Agency (ANEEL). This is to remunerate the capital invested by distribution companies while taking into account the composition 
TABLE 3: Weighted average cost of capital over time.

\begin{tabular}{lc}
\hline & WACC (pa) \\
\hline 1st cycle 2003/2006 & $11.26 \%$ \\
2nd cycle 2007/2010 & $9.98 \%$ \\
3rd cycle 2011/2014 & $9.15 \%{ }^{*}$ \\
\hline
\end{tabular}

${ }^{*}$ Forecast.

TABLE 4: Volatility of the project.

\begin{tabular}{ll}
\hline CA method & $6.90 \%$ \\
HP method & $9.89 \%$ \\
\hline
\end{tabular}

of capital structure as well as the costs associated with third party capital. The rate is established in each review cycle, with a tendency to stay unchanged for as long as possible so as to avoid questions from distributors who complete the review process at different times.

During the research, a forecasting study was conducted using the programs ForecastPRO and Crystal Ball. These considered historical data and the methodology used by ANEEL in its last review cycle. As a result, the forecast for the next WACC review is $9.15 \%$ p.a., with a relatively small standard deviation of $0.01 \%$, can be seen in Table 3 and Figure 2.

4.1.3. Volatility of the Project. So by analyzing the main exogenous variables of the project, we selected two main sources of uncertainty: demand and price. The combination of these variables will generate the volatility of the project.

However, prior to inserting the uncertainty of these variables into the project, we performed a correlation test between them, an essential step for effective modeling of uncertainties in the project. It was found, as expected, that the variables were independent and inelastic, characteristics that can be attributed to their satisfying basic needs for all consumers, industrial, commercial, and residential. This result was also obtained by Schmidt and Lima [12], where values were calculated that indicated the trend to low-price elasticity of electricity demand in the short term.

In spreadsheets of the project's discounted cash flow it was possible to perform Monte Carlo simulation using the Crystal Ball program, considering the uncertainty of the consolidated approach. The results for volatility using Copeland and Antikarov methods (CA) and Herath and Park (HP) during this stage can be seen in Table 4 .

The next step to obtain the value of flexibility is the creation of an event tree for each alternative.

To construct an event tree, the following variables are needed: present value (PV) of the underlying asset and the increments of ascent and descent. The latter are obtained through the volatility found in (6). The present value of the asset is the value of design to business minus the exercise price, in other words, the necessary investments for the realization of the project. In this case, the PV of the underlying asset are the benefits from implementing the project minus the additional costs of operation and maintenance as well as the taxes and fees.

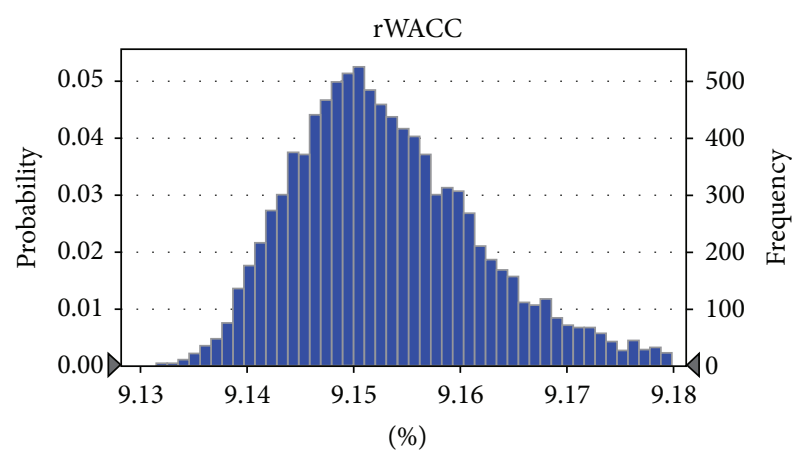

FIGURE 2: Graph of the probability distribution forecast WACC.

4.1.4. Application of Volatility to Obtain Results. The results of this step helped develop an event tree. The event tree shows what the possible values are that the project will take on over time. These values, regarding the market, are uncertainties, which compound will influence the value of the project in ascending and descending movements. According to Copeland and Antikarov [5], these up and down values are nothing more than geometric multiplicative factors.

Therefore considering the data of Step 1, a binomial grid of value was created of the underlying asset, as shown in Figures 3 and 4 . Note that the difference between each tree is the volatility, which was obtained through different methods. The event tree has nine stages. The rate used for discounting is the risk-free rate (6\%).

4.2. Incorporating Flexibility. The event tree provides the decision maker an idea of what the future possibilities are for the project under review. So at this stage, given the observed values in each branch of the tree of events, one can define what are the optimal decisions that might maximize the return on investment.

The investment will be carried out in three phases: short, medium, and long term. Since each phase is directly linked to the one prior, investing in the shortterm enables one to invest in the medium term. Investment in the medium term enables one to invest in the long term. It is on this basis that the long-term investment can only be executed if the two earlier investments are carried to the option's limit of expiration.

The short-term investment can be realized from Year 1 to Year 2. The medium-term investment can be realized from Years 4 to 5 . The long-term investment can be realized from Years 7 to 9, as can be seen in Table 5 .

Equation (9) is applied based on these investment restrictions, the event tree, and the tree data presented. The objective here is to maximize the value in each branch of the tree, with the values of the exercise price in the respective years. This step represents the decision making of the planners, who thus eliminate situations where the project fails:

$$
V_{O}=\operatorname{Max}\left(S_{T}-X ; 0\right) .
$$

By eliminating any possibility that the project value is negative, the decision maker has the power to make decisions that, empirically, he already had but which until then was not 


\begin{tabular}{|c|c|c|c|c|c|c|c|c|c|}
\hline $\begin{array}{c}\text { Year } \\
0\end{array}$ & $\begin{array}{c}\text { Year } \\
1 \\
\end{array}$ & $\begin{array}{c}\text { Year } \\
2 \\
\end{array}$ & $\begin{array}{c}\text { Year } \\
3 \\
\end{array}$ & $\begin{array}{c}\text { Year } \\
4\end{array}$ & $\begin{array}{c}\text { Year } \\
5\end{array}$ & $\begin{array}{c}\text { Year } \\
6\end{array}$ & $\begin{array}{c}\text { Year } \\
7 \\
\end{array}$ & $\begin{array}{c}\text { Year } \\
8\end{array}$ & $\begin{array}{c}\text { Year } \\
9\end{array}$ \\
\hline \multirow[t]{10}{*}{30.409} & 32.582 & 34.909 & 37.403 & 40.075 & 42.938 & 46.005 & 49.292 & 52.813 & 56.585 \\
\hline & 28.382 & 30.409 & 32.582 & 34.909 & 37.403 & 40.075 & 42.938 & 46.005 & 49.292 \\
\hline & & 26.490 & 28.382 & 30.409 & 32.582 & 34.909 & 37.403 & 40.075 & 42.938 \\
\hline & & & 24.723 & 26.490 & 28.382 & 30.409 & 32.582 & 34.909 & 37.403 \\
\hline & & & & 23.075 & 24.723 & 26.490 & 28.382 & 30.409 & 32.582 \\
\hline & & & & & 21.537 & 23.075 & 24.723 & 26.490 & 28.382 \\
\hline & & & & & & 20.101 & 21.537 & 23.075 & 24.723 \\
\hline & & & & & & & 18.760 & 20.101 & 21.537 \\
\hline & & & & & & & & 17.510 & 18.760 \\
\hline & & & & & & & & & 16.342 \\
\hline
\end{tabular}

FIgURE 3: Event tree volatility (CA) $(\mathrm{R} \$ * 000)$.

\begin{tabular}{|c|c|c|c|c|c|c|c|c|c|}
\hline $\begin{array}{c}\text { Year } \\
0\end{array}$ & $\begin{array}{c}\text { Year } \\
1\end{array}$ & $\begin{array}{c}\text { Year } \\
2\end{array}$ & $\begin{array}{c}\text { Year } \\
3\end{array}$ & $\begin{array}{c}\text { Year } \\
4\end{array}$ & $\begin{array}{c}\text { Year } \\
5\end{array}$ & $\begin{array}{c}\text { Year } \\
6\end{array}$ & $\begin{array}{c}\text { Year } \\
7\end{array}$ & $\begin{array}{c}\text { Year } \\
8\end{array}$ & $\begin{array}{c}\text { Year } \\
9\end{array}$ \\
\hline 30.409 & 33.571 & 37.061 & 40.913 & 45.166 & 49.862 & 55.045 & 60.767 & 67.084 & 74.058 \\
\hline & 27.546 & 30.409 & 33.571 & 37.061 & 40.913 & 45.166 & 49.862 & 55.045 & 60.767 \\
\hline
\end{tabular}

FiguRE 4: Event tree volatility $(\mathrm{HP})(\mathrm{R} \$ * 000)$.

TABLE 5: Investments in expansion plan.

$1^{\circ}$ Short-term investment ${ }^{*}$

$\mathrm{R} \$ 5,193.71$

$2^{\circ}$ Medium-term investment ${ }^{*}$

$\mathrm{R} \$ 13,776.65$

$3^{\circ}$ Long-term investment ${ }^{*}$

*Values in R\$1,000.00.

measured. The operation of maximizing the value branch-tobranch is performed in a backward manner, that is, from back to front. This is because the event tree makes plain all the values that the project could take on until the last period.

The result of this algorithm is trees of option values as seen in Figures 5 and 6 . But these are minor for decision makers, in terms of graphics, and can be translated through the decision trees that are shown in Figures 7 and 8.

4.3. Value of Options. After performing the calculations, it is possible to obtain a value for flexibility. According to Minardi [13], the net present value (NPV) can add the calculated flexibility by real options, generating the expanded NPV of

$$
\mathrm{VPL}_{\text {expanded }}=\mathrm{VPL}_{\text {Traditional }}+\text { Managerial flexibility. }
$$

Table 7 presents the results of net present value with the value of flexibility obtained by the real options theory. The greatest interest in obtaining this value happens when there is a list of projects that need approval based on budget constraints. In forming a company's portfolio of projects, one should consider not only the traditional methods of performance evaluation but also the criterion of flexibility that every opportunity will bring to the company, that is, the strategic value of the project.

\subsection{Analysis of Results}

4.4.1. Methodology for Interpretation of Results. Ross et al. [14] claim that there is a fundamental difference between applying variability to an option involving an active object and applying the underlying asset itself. If investors are risk averse, an increase in the underlying asset's variability will reduce its market value. However, in the case of financial options, the option holder receives positive results due to the increased volatility and the positive tail of the probability distribution.

Therefore, there is a basic difference to consider in the volatility of real options and that of financial options. Therefore, the higher the volatility, the greater the value of the option or sale. But when it comes to a real asset, this is not true. A real asset must have a small margin for error in planning.

According to Table 6, the consolidated approach to uncertainty by the HP method produces higher volatility values than does the same approach using the CA method. 


\begin{tabular}{|c|c|c|c|c|c|c|c|c|c|}
\hline $\begin{array}{c}\text { Year } \\
0\end{array}$ & $\begin{array}{c}\text { Year } \\
1\end{array}$ & $\begin{array}{c}\text { Year } \\
2\end{array}$ & $\begin{array}{c}\text { Year } \\
3\end{array}$ & $\begin{array}{c}\text { Year } \\
4\end{array}$ & $\begin{array}{c}\text { Year } \\
5\end{array}$ & $\begin{array}{c}\text { Year } \\
6\end{array}$ & $\begin{array}{c}\text { Year } \\
7\end{array}$ & $\begin{array}{c}\text { Year } \\
8\end{array}$ & $\begin{array}{c}\text { Year } \\
9\end{array}$ \\
\hline \multirow[t]{10}{*}{5.506} & 6.174 & 6.917 & 13.237 & 14.459 & 15.785 & 31.826 & 34.262 & 36.881 & 39.698 \\
\hline & 2.093 & 2.419 & 8.416 & 9.293 & 10.250 & 25.896 & 27.908 & 30.073 & 32.404 \\
\hline & & 0 & 4.231 & 4.793 & 5.429 & 20.730 & 22.373 & 24.143 & 26.050 \\
\hline & & & 920 & 1.063 & 1.229 & 16.230 & 17.552 & 18.978 & 20.515 \\
\hline & & & & 0 & 0 & 12.310 & 13.352 & 14.478 & 15.694 \\
\hline & & & & & 0 & 8.896 & 9.694 & 10.558 & 11.494 \\
\hline & & & & & & 5.922 & 6.507 & 7.143 & 7.836 \\
\hline & & & & & & & 3.734 & 4.169 & 4.649 \\
\hline & & & & & & & & 1.621 & 1.873 \\
\hline & & & & & & & & & 0 \\
\hline
\end{tabular}

Figure 5: Tree CA values $(\mathrm{R} * \$ 000)$.

\begin{tabular}{|c|c|c|c|c|c|c|c|c|c|}
\hline $\begin{array}{c}\text { Year } \\
0\end{array}$ & $\begin{array}{c}\text { Year } \\
1\end{array}$ & $\begin{array}{c}\text { Year } \\
2\end{array}$ & $\begin{array}{c}\text { Year } \\
3\end{array}$ & $\begin{array}{c}\text { Year } \\
4\end{array}$ & $\begin{array}{c}\text { Year } \\
5\end{array}$ & $\begin{array}{c}\text { Year } \\
6\end{array}$ & $\begin{array}{c}\text { Year } \\
7\end{array}$ & $\begin{array}{c}\text { Year } \\
8\end{array}$ & $\begin{array}{c}\text { Year } \\
9\end{array}$ \\
\hline 5.643 & 7.172 & 9.068 & 16.747 & 19.550 & 22.708 & 40.866 & 45.737 & 51.153 & 57.171 \\
\hline \multirow{2}{*}{1.805} & 2.459 & 9.404 & 11.444 & 13.760 & 30.987 & 34.832 & 39.113 & 43.880 \\
\cline { 3 - 11 } & 0 & 3.579 & 4.793 & 6.417 & 22.881 & 25.883 & 29.235 & 32.974 \\
\hline
\end{tabular}

FIgURE 6: Tree of values (HP) (U.S. $\$ 000 *$ ).

TABLE 6: Value of flexibility.

Flexibility value $\mathrm{CA}^{*}$

Flexibility value $\mathrm{HP}^{*}$

$\mathrm{R} \$ 5,505.91$

Difference (\%)

${ }^{*}$ Values in R $\$ 1,000.00$.

TABLE 7: Net present value with flexibility.

Inelastic NPV

$\mathrm{R} \$ 14,064.79$

NPV with flexibility CA

$\mathrm{R} \$ 19,570.70$

NPV with flexibility HP

$\mathrm{R} \$ 19,707.38$

Values in $\mathrm{R} \$ 1.000,00$.

The choice to use a consolidated approach to uncertainty is justified mainly by its use in the literature. In addition to other works in the area, Brandão et al. [15] and Miller and Park [16] also offer a full explanation of the subject, making a demonstration of the theory.

According to Godinho [17], both the CA and HP methods used by Cobb and Charnes [18] are wrong because they overestimate volatility. Godinho [17] argues that, since volatility changes over time and also the value of the project, the idea of CA in calculating volatility over the first period is not valid. To solve the problem of variation of volatility with respect to time, volatility can be calculated for each period of the project. However, if the volatility changes over periods together with the value of the project design that would become unviable another issue is to consider this equation in projects where cash flows are negative or the initial present value is negative.

Godinho [17] also holds that the HP method overestimates the value of further volatility, simulating the NPV at time zero, since this value should be the expected value of the project. To solve the problem of calculating the volatility, the author suggests some simulation steps, where the expected values are considered as the project's value and not values that occurred. According to this methodology, a simulation is performed in the first year with the data obtained so far, then simulations are performed for the subsequent years, considering the outcome of the first simulation as input data and so on.

Similarly, Smith [19] criticizes the use of the consolidated approach of uncertainty through the method of CA used by Brandão et al. [15] for overestimating volatility. In contrast, Brandão et al. [15] argue further that they can use the standard deviation of return of the project in Period 1. This can be done to properly specify the parameters of volatility in the stochastic process, if the values follow a geometric Brownian motion with constant volatility. However, they redo their calculations according to the specifications of Smith 


\begin{tabular}{|c|c|c|c|c|c|c|c|c|c|}
\hline $\begin{array}{c}\text { Year } \\
0\end{array}$ & $\begin{array}{c}\text { Year } \\
1\end{array}$ & $\begin{array}{c}\text { Year } \\
2\end{array}$ & $\begin{array}{c}\text { Year } \\
3\end{array}$ & $\begin{array}{c}\text { Year } \\
4\end{array}$ & $\begin{array}{c}\text { Year } \\
5\end{array}$ & $\begin{array}{c}\text { Year } \\
6\end{array}$ & $\begin{array}{c}\text { Year } \\
7\end{array}$ & $\begin{array}{c}\text { Year } \\
8\end{array}$ & $\begin{array}{c}\text { Year } \\
9\end{array}$ \\
\hline \multirow[t]{10}{*}{ Wait } & Wait & Invest & Wait & Wait & Invest & Wait & Wait & Wait & Invest \\
\hline & Wait & Invest & Wait & Wait & Invest & Wait & Wait & Wait & Invest \\
\hline & & Quit & Wait & Wait & Invest & Wait & Wait & Wait & Invest \\
\hline & & & Wait & Wait & Invest & Wait & Wait & Wait & Invest \\
\hline & & & & Quit & Quit & Wait & Wait & Wait & Invest \\
\hline & & & & & Quit & Wait & Wait & Wait & Invest \\
\hline & & & & & & Wait & Wait & Wait & Invest \\
\hline & & & & & & & Wait & Wait & Invest \\
\hline & & & & & & & & Wait & Invest \\
\hline & & & & & & & & & Quit \\
\hline
\end{tabular}

Figure 7: Decision tree (CA).

\begin{tabular}{|c|c|c|c|c|c|c|c|c|c|}
\hline $\begin{array}{c}\text { Year } \\
0 \\
\end{array}$ & $\begin{array}{c}\text { Year } \\
1 \\
\end{array}$ & $\begin{array}{c}\text { Year } \\
2 \\
\end{array}$ & $\begin{array}{c}\text { Year } \\
3 \\
\end{array}$ & $\begin{array}{c}\text { Year } \\
4 \\
\end{array}$ & $\begin{array}{c}\text { Year } \\
5 \\
\end{array}$ & $\begin{array}{c}\text { Year } \\
6 \\
\end{array}$ & $\begin{array}{c}\text { Year } \\
7 \\
\end{array}$ & $\begin{array}{c}\text { Year } \\
8 \\
\end{array}$ & $\begin{array}{c}\text { Year } \\
9 \\
\end{array}$ \\
\hline \multirow[t]{10}{*}{ Wait } & Wait & Invest & Wait & Wait & Invest & Wait & Wait & Wait & Invest \\
\hline & Wait & Invest & Wait & Wait & Invest & Wait & Wait & Wait & Invest \\
\hline & & Quit & Wait & Wait & Invest & Wait & Wait & Wait & Invest \\
\hline & & & Wait & Wait & Invest & Wait & Wait & Wait & Invest \\
\hline & & & & Quit & Quit & Wait & Wait & Wait & Invest \\
\hline & & & & & Quit & Wait & Wait & Wait & Invest \\
\hline & & & & & & Wait & Wait & Wait & Invest \\
\hline & & & & & & & Wait & Wait & Invest \\
\hline & & & & & & & & Quit & Quit \\
\hline & & & & & & & & & Quit \\
\hline
\end{tabular}

FIgURE 8: Decision tree (HP).

[19], which are considered the conditional expected values and thus find a better estimate of volatility.

So what has been perceived through this earlier work is that there are still doubts about the best approach to estimating volatility. The new proposal by Godinho [17], also similar to that quoted by Smith [19] and calculated by Brandão et al. [15], appears to be more accurate in its application but is not yet widespread among more recent authors who continue to use the consolidated approach of uncertainty.

Because of this reasoning and proof, the consolidated approach of uncertainty was selected for use in calculating the volatility of this issue of real options.

4.4.2. Obtained Results. Analyzing the different methods based on this methodology (CA and HP), it was found that, as expected, each method's results were distinct but had a difference of only 2.99 percentage points, relatively small compared to the examples in the literature.

Hence, in the case of this distribution, the different methods showed little variation in the definition of scenarios, precisely because the volatility had little variation. Consequently, the difference in the value of flexibility between the models is $\mathrm{R} \$ 136,678$, representing only $2.5 \%$ of the total flexibility.

The main reason for this small difference in the models is the low variance of demand and price variables, which are reasonably foreseeable and are not related to this case.

\section{Conclusions}

It is known that traditional forms of assessment do not reflect the real value of projects. An administrator who relies solely on the mathematical results they are presented will see their project portfolio erroneously.

This paper carried out the application and verification of the approaches used in the calculation of volatility. Since this aspect is paramount to calculating the net present value with flexibility, very little has been done so far. On one point all authors agree: the key to achieving flexibility is the effective modeling of uncertainties in future scenarios. But how such modeling is done still generates a great deal of discussion, and most authors have not explored this field that is essential to the success of the calculation.

The main objective of this paper was to present an analysis of investments with volatility, from their modeling to calculation and the conclusion. Volatility was calculated by 
the consolidated approach of uncertainty, for the CA and HP models. There was a slight difference between the methods in this case, which can be attributed to the good predictability of the market demand study and to price, which is strongly regulated by the department of electricity.

In conclusion, it turns out that the decision in this case was not altered to be in accordance with the results obtained for each type of volatility. However, it is necessary to conduct further experiments with different cases, cases where the variables have greater variability.

Through this analysis of investments having volatility, it can be concluded in this case that even when the variables have low volatility, value is expected. And that the different models to obtain the volatility in the problem analyzed produce very similar results.

\section{Acknowledgments}

The authors would like to express their gratitude to the Brazilian agencies q National Counsel of Technological and Scientific Development (CNP), post-graduate federal agency (CAPES), and foundation for the promotion of science of the state of minas gerais (FAPEMIG), which have been supporting the efforts for the development of this work in different ways and periods.

\section{References}

[1] J. Mun, Real Options Analysis, Wiley Finance, 2002.

[2] H. Brasil, J. F. Marreco, V. I. Martins, D. S. Gonçalves, and E. Ribeiro, Opções Reais-Conceitos Aplicações a Empresas e Negócios, Editora Saraiva, 2007.

[3] T. Eschenbach, N. Lewis, M. Henrie, E. Baker IV, and J. C. Hartman, "Real options and real engineering projects," Engineering Management Journal, vol. 19, no. 4, pp. 11-19, 2007.

[4] T. E. Copeland and P. Tufano, "A real-world way to manage real options," Harvard Business Review, vol. 82, no. 3, pp. 90-128, 2004.

[5] T. E. Copeland and V. Antikarov, Opções Reais: Um Novo Paradigma para Reinventar a Avaliação de Investimentos, Campus, Rio de Janeiro, Brazil, 2001.

[6] C. S. Park, Contemporary Engineering Economics, Prentice Hall, 4th edition, 2007.

[7] J. C. Cox, S. A. Ross, and M. Rubinstein, "Option pricing: a simplified approach," Journal of Financial Economics, vol. 7, no. 3, pp. 229-263, 1979.

[8] F. Black and M. Scholes, "The pricing of options and corporate liabilities," Journal of Political Economy, no. 81, pp. 637-659, 1973.

[9] P. Samuelson, "Proof that properly anticipated prices fluctuate randomly, Industrial Management Review, vol. 6, pp. 41-49, 1965.

[10] H. S. Herath and C. S. Park, "Multi-stage capital investment opportunities as compound real options," The Engineering Economist, vol. 47, no. 1, 2002.

[11] J. W. M. Bertrand and J. C. Fransoo, "Operations management research methodologies using quantitative modeling," International Journal of Operations and Production Management, vol. 22, no. 2, pp. 241-264, 2002.
[12] C. A. Schmidt and M. A. Lima, Estimações e Previsões da Demanda por Energia Elétrica no Brasil, work 16, Secretária de Apoio Econômico-Ministério da Fazenda, 2002.

[13] A. M. Minardi, "Teoria de opções reais aplicada a projetos de investimentos," Revista de Administração de Empresas, vol. 40, no. 2, pp. 74-79, 2000.

[14] S. Ross, R. W. Westerfield, and J. F. Jaffe, Corporate Finance, Editora Atlas, São Paulo, Brazil, 2nd edition, 2002.

[15] L. E. Brandão, J. S. Dyer, and W. J. Hahn, "Using binomial decision trees to solve real-option valuation problems," Decision Analysis, vol. 2, no. 2, pp. 69-88, 2005.

[16] L. Miller and C. S. Park, "Decision making under uncertaintyreal options to the rescue?" The Engineering Economist, vol. 47, no. 2, 2002.

[17] P. M. Godinho, Monte Carlo Estimation of Project Volatility for Real Options Analysis, GEMF-Faculdade de Economia, Universidade de Coimbra, 2006.

[18] B. R. Cobb and J. M. Charnes, "Real options volatility estimation with correlated inputs," The Engineering Economist, vol. 49, no. 2, pp. 119-137, 2004.

[19] J. E. Smith, "Alternative approaches for solving real-options problems," Decision Analysis, vol. 2, no. 2, pp. 89-102, 2005. 


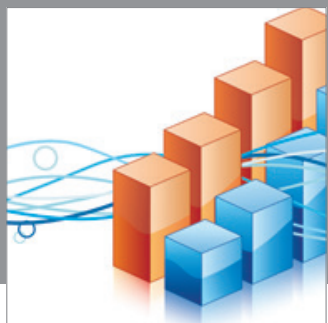

Advances in

Operations Research

mansans

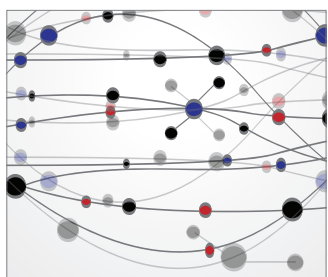

The Scientific World Journal
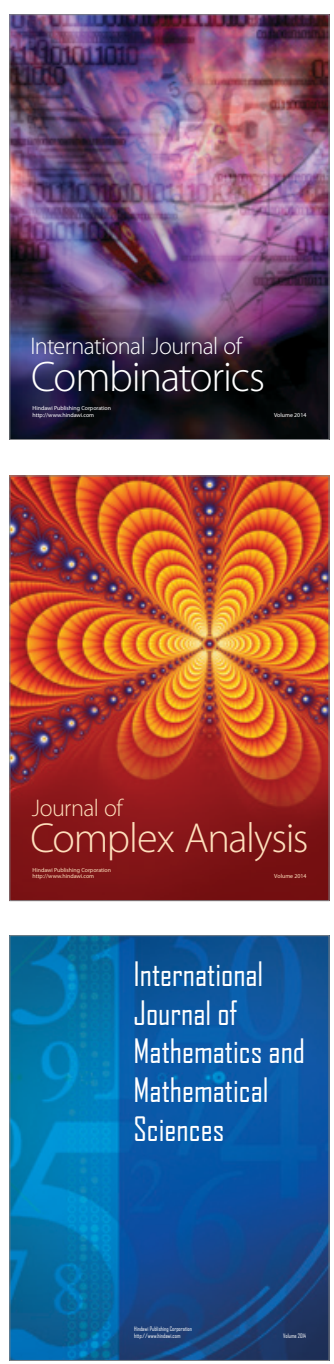
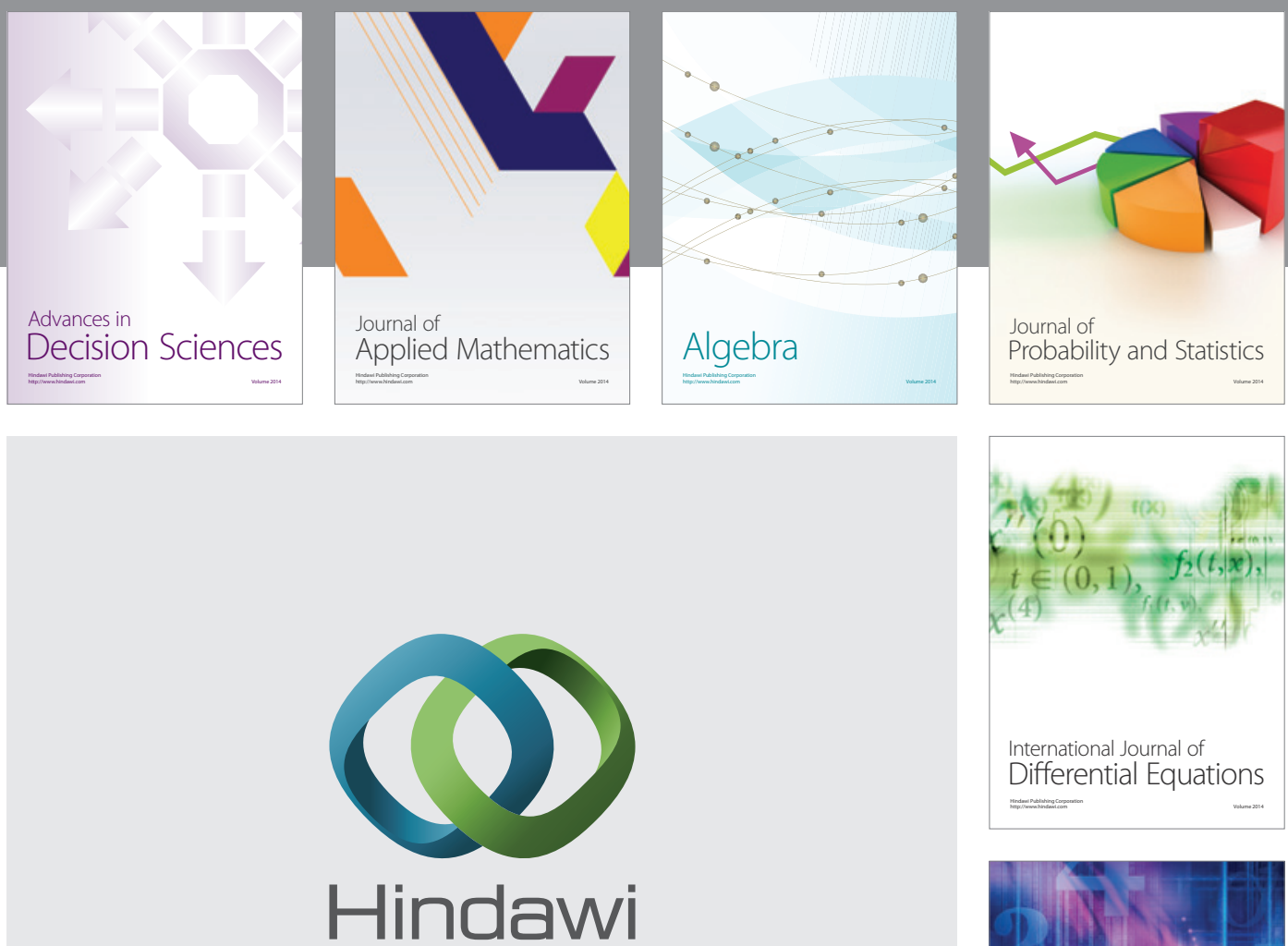

Submit your manuscripts at http://www.hindawi.com
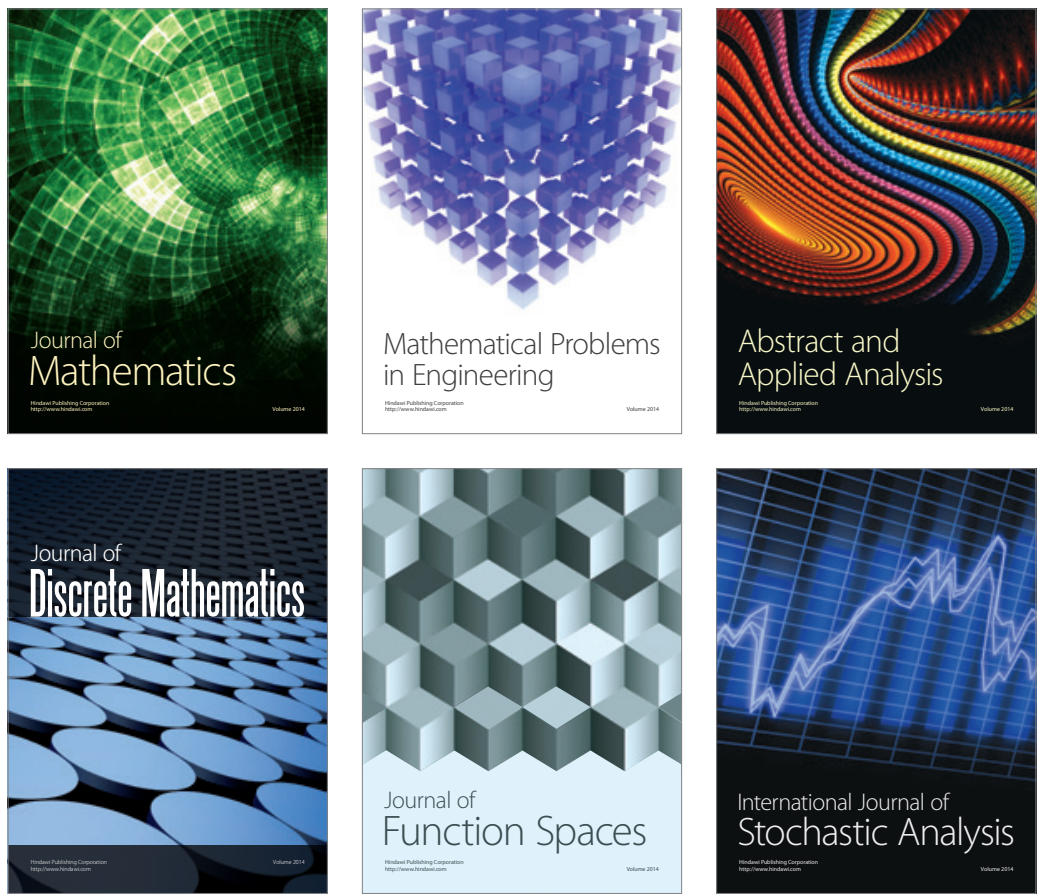

Journal of

Function Spaces

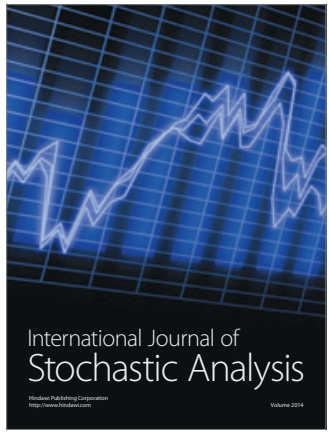

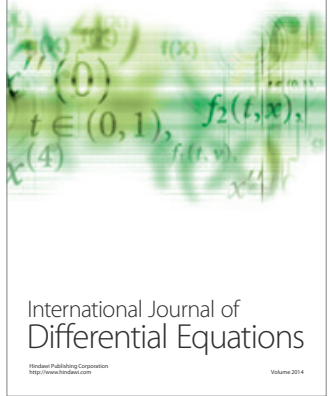
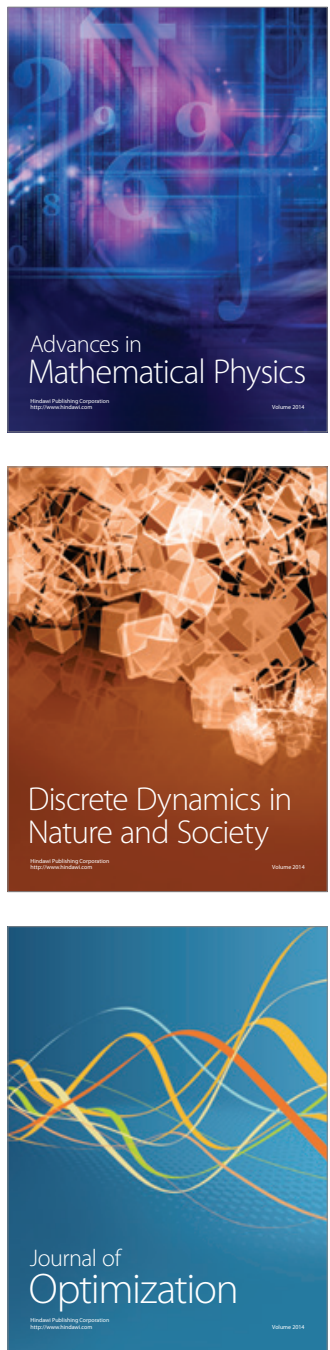